\title{
Leben ohne Warum
}

\section{Jean Martin}

Dr. med., Mitglied der Redaktion

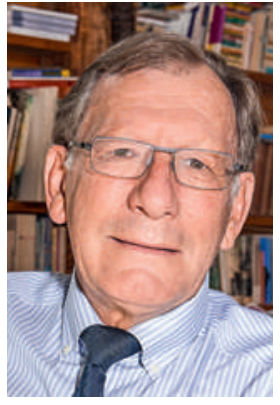

Diverse Bücher von Alexandre Jollien sind auch auf Deutsch erhältlich, darunter Das Lob de Schwachheit (2001, rezensiert von $\mathrm{E}$. Taverna, SÄZ 26/2001) und Die Kunst,

Mensch zu sein (2003) beide Pendo-Verlag.

Literatur

1 Angelus Silesiu (deutscher Lyriker und Mystiker des 17 . Jahrhunderts). Cherubinischer Wandersmann. Zürich: Diogenes; 2006

2 Jollien A. Vivre sans pourquoi - Itinéraire spirituel d'un philosophe en Corée.

Paris: L'Iconoclaste/ Seuil; 2015.

3 Interview in Le Temps (Genf), 7. März 2015

jean.martin[at]saez.ch
«Die Rose ist ohne Warum, sie blühet, weil sie blühet ...» [1]. Eine zum Nachdenken anregende Aussage, die das jüngste Werk von Alexandre Jollien inspiriert hat [2]. Es muss wohl nicht daran erinnert werden, dass dieser 1975 im Wallis geborene und seit seiner Geburt schwerbehinderte Philosoph sein Leben bis zum Alter von 20 Jahren in Spezialschulen verbracht hat. In der Folge machte er mit wichtigen Werken auf sich aufmerksam - im Zusammenhang mit den grossen Herausforderungen, mit denen er sich konfrontiert sieht (Das Lob der Schwachheit* erschien als erstes Werk im Jahr 1999).

Auf seiner Suche befasst sich Jollien - Christ, der er ist und bleibt - auch mit anderen spirituellen Denkrichtungen, darunter vor allem mit dem Buddhismus. Im Sommer 2013 reist er mit Frau und Kindern nach Seoul, um dort im Kontakt mit einem kanadischen Jesuiten und Zen-Meister $\mathrm{zu}$ «wagen, die spirituelle Praxis in den Mittelpunkt meines Lebens zu stellen». Leben ohne Warum zeichnet diese Erfahrung nach [2]. Für die Journalistin L. Koutchoumoff ist es ein ungeschminktes Tagebuch dieses radikalen und gleichzeitig fröhlichen Weges. Ganz im Alltag, im Körper verankert, wirkt die Suche inspirierend und nährt den Geist. Und wirft Fragen auf [3].

Ein interessanter Bericht über die Gedanken und Wege des Autors in Seoul und auf dem Land. Angetrieben von dem Wunsch, Freunde zu gewinnen, erkundet und reist er, verbringt Stunden in Bars - gelegentlich auch übel beleumundeten -, öffentlichen Bädern, in Begleitung eines koreanischen Bekannten namens Junho, voller Begeisterung und Leichtigkeit (so Jollien).

Leben ohne Warum. «Leben ohne Warum heisst zu lernen, sich durch den Blick des anderen nicht vollständig konditionieren zu lassen. Etwas Abstand zu nehmen von der Diktatur des 'danach' [...], des 'ich hätte müssen' oder 'wenn doch nur', um besser in der Realität anzukommen.» "Die Freude besteht in der Befreiung, dem Freischaufeln. Immer im Hier und Jetzt verweilen. Ja zu sagen zu allem, was einem begegnet. Chaos und Traumata kommen lassen, ohne zu intervenieren.»

«Eine Schwindel erregende Herausforderung: Weniger Automatismen im Leben, das Ego abtöten [...] Mit Hilfe des Zen beginne ich langsam hinzuhören.»

Dem Christentum und dem Buddhismus verbunden sein zu wollen ist nicht ganz einfach: «Einerseits beklagen die Buddhisten, ich sei nicht genug Buddhist, ohne zu verstehen, dass ich an einen Gott glaube, der sich in Jesus offenbart hat. Andererseits werfen mir einige
Christen ernsthaft vor, mich auf Abwege zu begeben.» Er erinnert an die Bedeutung der "noblen Weisheiten" aus dem Buch Kohelet: Windhauch, Windhauch, das ist alles Windhauch; es gibt eine Zeit für alles, eine Zeit zum Lachen und zum Weinen, eine Zeit zum Geborenwerden und zum Sterben. Man muss sich an der Sonne erfreuen und ganz einfach die Freude am Leben geniessen.

Hören, Zweifeln - Sind wir Herr der Dinge? «Ganz auf Gott bauen, ohne Warum - nicht einmal wegen eines Paradieses. Ehrlich gesagt ist mir das Leben nach dem Tod mehr oder weniger egal.» "Der Zweifel schützt mich vor der Versuchung, Gott zu einem Götzen zu machen. Ich weiss nicht, wer Gott ist, ich fühle eine diskrete Präsenz, das ist alles. Das Leben ausserhalb der Wahrnehmung. Wir sind nicht Herr der Dinge.»

Jollien will keinen Gott, der Schuld zuweist: «Warum sollen wir in Gott das lästige schlechte Gewissen sehen? Wenn es Gott gibt, ist er ganz sicher unser Schuldenvergeber par excellence.» «Dieses grosse Missverständnis, den Glauben zu einer bedrückenden, belastenden Sache zu machen.» Körper und Geist. «Wir müssen unseren Körper pflegen, damit die Seele gerne darin wohnt. Sport treiben, den Geruch seines Kindes wahrnehmen, essen, trinken.» Und: "Auf dieser Reise nach Asien gibt es kein Entkommen: Sie zwingt mich dazu, erneut der Aussage nachzugehen: Auf sich achten.» "In öffentlichen Bädern geschieht gelegentlich das Wunder, die Barriere zwischen mir und meinem Körper löst sich auf.»

Sich von der Idee des Heilens befreien. «Ich beginne zu begreifen, dass der Arzt mich nicht heilen kann [...] Die eigentliche Gesundheit besteht darin, mit seinen Schwächen, den unheilbaren Krankheiten, den tausendundein Verletzungen zu leben.»

«Es geht vor allem darum, sich selbst etwas zurückzunehmen, [aber] Achtung, zurückzunehmen, nicht sich zu vernachlässigen.» "Askese lässt sich zu einem beruhigenden Paradoxon resümieren: Auf sich achten, ohne viel Lärm um sich zu machen.» "Sich mit der Unvollkommenheit der Welt versöhnen, genau das meint die Askese, die Konversion.»

Und an die Adresse aller Hyperaktiven: «Die Versuchung, leeren Raum ausfüllen zu wollen, ist sehr gross [...] Wie grob, Ruhe mit Leere und Langeweile zu assoziieren.»

NB: Man muss nicht selbst an die Transzendenz glauben, um den Weg der «Brüder in der Menschlichkeit», zu denen Alexandre Jollien zählt, stimulierend zu finden. 